\title{
A Comparative Study of Smear Layer Removal and Erosion in Apical Intraradicular Dentine With Three Irrigating Solutions: A Scanning Electron Microscopy Evaluation
}

\author{
Manuele Mancini, DDS, ${ }^{*}$ Emiliano Armellin, DDS, * Adriano Casaglia, DDS, ${ }^{\dagger}$ \\ Loredana Cerroni, DDS, ${ }^{+}$and Luigi Cianconi, $M D, D D S^{*}$
}

\begin{abstract}
Introduction: This study compared the efficacy of BioPure MTAD (Dentsply Tulsa, Tulsa, OK), 17\% EDTA, and $42 \%$ citric acid in endodontic smear layer removal and degree of erosion in the apical third of endodontic canals. Methods: Ninety-six extracted single-rooted human teeth were randomized into four groups $(n=24)$ and instrumented using System GT nickel-titanium rotary instruments (Dentsply Tulsa, Tulsa, OK). Each canal was irrigated with one of the following solutions: BioPure MTAD, $17 \%$ EDTA, $42 \%$ citric acid, or $5.25 \% \mathrm{NaOCl}$ (control). Next, all specimens were irrigated with $5.25 \% \mathrm{NaOCl}$. Results: Evaluation by scanning electron microscopy showed no significant differences among test irrigants in removing the smear layer. However, the efficacy of BioPure MTAD and 17\% EDTA in removing the smear layer was significantly greater than $5.25 \%$ $\mathrm{NaOCl}$ (control). The erosive effects of irrigating solutions could not be evaluated. Conclusions: In conclusion, the protocols used in this study were not sufficient to completely remove the smear layer in the apical third of prepared root canals. (J Endod 2009;35:900-903)
\end{abstract}

\section{Key Words}

BioPure MTAD, citric acid, EDTA, irrigation, smear layer

From the Departments of * Restorative Dentistry and Endodontics and 'Dental Materials, University of Rome "Tor Vergata," Rome, Italy.

Address requests for reprints to Dr Manuele Mancini, Via Tuscolana 58-00182 Rome, Italy. E-mail address: manuele. mancini@tiscali.it.

0099-2399/\$0 - see front matter

Copyright (C) 2009 American Association of Endodontists. doi:10.1016/j.joen.2009.03.052
S tudies have shown that mechanical instrumentation of root canals leaves a smear

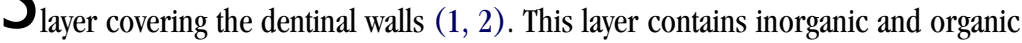
material (1). Despite controversy over maintaining the smear layer, it has been shown that the smear layer itself may contain bacteria and protect the bacteria within the dentinal tubules (3). The smear layer has also been shown to hinder the penetration of intracanal disinfectants (4) and sealers (5) into dentinal tubules and can potentially compromise the seal of the root canal filling $(6,7)$.

The alternating use of EDTA and sodium hypochlorite $(\mathrm{NaOCl})$ has been recommended for the efficient removal of the smear laver $(8-10)$. However, there is concern that this combined irrigation regimen causes inadvertent erosion of the intraradicular dentin (11-14). Although doxycycline, a tetracycline isomer, and citric acid have been used separately for removing the endodontic smear layer, the introduction of MTAD (15), an aqueous solution of $3 \%$ doxycycline, $4.25 \%$ citric acid, and $0.5 \%$ polysorbate 80 detergent (16), represents a clinical effective endodontic irrigation technique (17). This biocompatible intracanal irrigant (18) is commercially available as a two-part mix (BioPure MTAD; Dentsply Tulsa, Tulsa, OK). In this product, doxycycline hyclate is used instead of its free base, doxycycline monohydrate, to increase the water solubility of this broad-spectrum antibiotic (19).

MTAD has been reported to be effective in removing the smear layer (14), eliminating microbes that are resistant to conventional endodontic irrigants and medications (20) and providing sustained antimicrobial activity through the binding affinity of doxycycline for dental hard tissues (21). Similar to EDTA, initial rinsing of instrumented root canals with dilute $\mathrm{NaOCl}$ is recommended for enhancing the efficacy of MTAD in dissolving endodontic the smear layer (14). Unlike the use of EDTA, minimal erosion of intraradicular dentin has been reported when $\mathrm{NaOCl}$ and MTAD were used as the final rinse (14).

Citric acid may also be used for smear laver removal. Concentrations ranging from $1 \%$ to $50 \%$ have been investigated (22-26), but $42 \%$ citric acid has never been tested before. Wayman et al (24) showed that the use of $10 \%$ citric acid and $2.5 \% \mathrm{NaOCl}$ is a very effective approach for smear layer removal. Di Lenarda et al (27) reported no or negligible difference in smear layer removal with citric acid and EDTA.

A review of the current literature showed a lack of reports regarding the comparison of three different irrigants' ability to remove the endodontic smear layer in the apical third of instrumented canals. Hence, this study aimed to assess the smear layer removal ability and the erosive effects of BioPure MTAD, EDTA 17\%, and citric acid 42\% through scanning electron microscopic (SEM) digital image analysis of the apical third of instrumented root canals.

\section{Tooth Selection}

\section{Materials and Methods}

Ninety-six periodontally involved human maxillary central incisors with single straight root canal extracted from 35- to 60-year-old patients were selected with the approval of the Ethics in Research Committee of the Centre of Health Sciences of the University of Rome "Tor Vergata." The teeth were devoid of caries, cracks, endodontic treatments, or restorations. Only teeth with intact and mature root apices were selected. 
After extraction, teeth were stored in $2 \%$ thymol solution at room temperature and used within 1 week.

\section{Root Canal Preparation}

The teeth were decoronated to standardized root length of $12 \mathrm{~mm}$ and randomly divided into one of four groups $(n=24)$. The working lengths were measured by deducting $1 \mathrm{~mm}$ from lengths recorded when the tips of \#10 or \#15 K-files (Dentsply Maillefer, Ballaigues, Switzerland) were visible at the apical foramina. The specimens were shaped using System GT Ni-Ti rotary instruments (Dentsply Maillefer, Ballaigues, Switzerland) according to the manufacturer's instructions until System GT \#30/.04 file reached the working length. Each instrument was only used for the preparation of four teeth. After using each file and before proceeding to the next, canals were irrigated with $2 \mathrm{~mL}$ of $5.25 \% \mathrm{NaOCl}$ at $37^{\circ} \mathrm{C}$ (Chematek SpA). After instrumentation, all teeth underwent final irrigation as follows: (1) MTAD group, $1 \mathrm{~mL}$ of MTAD for 1 minute followed by $3 \mathrm{~mL}$ of $5.25 \% \mathrm{NaOCl} 37^{\circ} \mathrm{C}$; (2) EDTA group, $1 \mathrm{~mL}$ of $17 \%$ EDTA (Chematek SpA) for 1 minute followed by $3 \mathrm{~mL}$ of $5.25 \% \mathrm{NaOCl} 37^{\circ} \mathrm{C}$; (3) citric acid group, 1 $\mathrm{mL}$ of $42 \%$ citric acid (Chematek SpA) for 1 minute followed by 3 $\mathrm{mL}$ of $5.25 \% \mathrm{NaOCl} 37^{\circ} \mathrm{C}$; and (4) control group, $1 \mathrm{~mL}$ of $5.25 \%$ $\mathrm{NaOCl} 37^{\circ} \mathrm{C}$ for 1 minute followed by $3 \mathrm{~mL}$ of $5.25 \% \mathrm{NaOCl} 37^{\circ} \mathrm{C}$.

The irrigating solutions were delivered via a sterile 30-gauge nickel-titanium needle (Stropko NiTi Flexi-Tip; SybronEndo, Orange, $\mathrm{CA}$ ), which penetrated to within 1 to $2 \mathrm{~mm}$ of the working length. The root canals then were irrigated with $5 \mathrm{~mL}$ of distilled water and dried with sterile paper points.

\section{Specimen Preparation}

An SEM was used to evaluate endodontic smear layer removal ("cleanliness") and erosion in the apical third of the instrumented root canals. To prepare the samples for imaging, the teeth/roots were usually split longitudinally in the buccolingual plane. To facilitate fracture into two halves, all roots were grooved longitudinally on the external surface with a diamond disc, avoiding penetration of the root canals. The roots were then split in two halves with a chisel. For each root, the half containing the most visible part of the apex was conserved and coded. The coded specimens were secured on metal stubs, desiccated, sputter coated with gold, and viewed with SEM (Digital scanning microscope, DSM 950; Carl Zeiss, Oberkochen, Germany).

\section{SEM Evaluation}

The cleanliness and degree of erosion was evaluated at $2 \mathrm{~mm}$ from the apical foramen of each canal wall and photographed at $2,000 \times$ magnification. The views were divided into 16 subareas by overlaying a grid. Blind evaluation was performed independently by two observers after the examination of 20 specimens jointly for calibration purposes. Intraexaminer and interexaminer reliability for the SEM assessment was verified by the Kappa test. Cleanliness was evaluated using a three-point scoring system codified by Torabinejad et al (15), which measured the presence, quantity, and distribution of the smear layer as follows: score $0=$ no smear layer (no smear layer on the surface of the root canals with all tubules clean and open), score $1=$ moderate smear layer (no smear layer on the surface of root canals but tubules contain debris), and score 2 = heavy smear layer (smear layer covers the root canal surface and the tubules). The same observers scored the degree of erosion of dentinal tubules as follows: score $0=$ no erosion (all tubules look normal in appearance and size), score $1=$ moderate erosion (peritubular dentin is eroded), and score 2 = severe erosion (intertubular dentin is destroyed, and tubules are connected to each
TABLE 1. Statistical Analysis on the Presence/Absence of the Smear Layer and the Degree of Erosion

\begin{tabular}{|c|c|c|c|c|}
\hline & \multicolumn{2}{|c|}{$\begin{array}{l}\text { Average } \\
\text { Cleanliness }\end{array}$} & \multicolumn{2}{|c|}{$\begin{array}{c}\text { Average } \\
\text { Erosion }\end{array}$} \\
\hline $17 \%$ EDTA group & 1.75 & & 0.01 & \\
\hline $42 \%$ Citric acid group & 1.94 & & 0.03 & \\
\hline MTAD group & 1.75 & & 0.04 & \\
\hline Control group & 2 & & 0 & \\
\hline \multicolumn{5}{|l|}{ Cleanliness } \\
\hline $17 \%$ EDTA group & vs & Con & group & $p<0.05$ \\
\hline MTAD group & vs & Con & group & $p<0.05$ \\
\hline
\end{tabular}

EDTA, ethylenediaminetetraacetic acid; MTAD, mixture of tetracycline isomer, acid, and detergent.

other). Data were analyzed by using Kruskal-Wallis and Mann-Whitney $U$ tests; $p$ values were computed and compared with statistical significance at the $\mathrm{p}=0.05$ level.

\section{Results}

Kappa test results, with a significance set at 0.5 , showed good intraexaminer and interexaminer agreement with values ranging from 0.90 and above for the different groups. (Table 1) shows cleanliness and degree of erosion findings. Specimens treated with 17\% EDTA (EDTA group) showed a thick smear layer and smear plugs in the apical portion; virtually no erosion was seen in any specimen of the EDTA group (Fig. 1). Samples treated with $42 \%$ citric acid for 1 minute (citric acid group) showed a heavy smear layer in the apical third similar to the control group (Fig. 1). In 2 out of 12 samples of the citric acid group (Fig. 1), less scattered remnants were seen, whereas other samples showed a very low score for erosion. Samples treated with BioPure MTAD for 1 minute (MTAD group) showed a heavy presence of a smear layer (Fig. 1). The degree of erosion could not be statistically evaluated because of the few areas devoid of smear layer among the specimens. Samples in the $5.25 \% \mathrm{NaOCl} 37^{\circ} \mathrm{C}$ (control group) showed a heavy smear layer (Fig. 1).

\section{Statistical Analysis}

Table 1 shows results of the statistical comparison between groups for cleanliness. Significant values were between $p<0.05$ and $\mathrm{p}<0.0001$. No significant difference in cleanliness was found between the control group and citric acid group, whereas the EDTA group and MTAD group showed significant differences with control (both $\mathrm{p}<$ 0.05). The EDTA and MTAD groups exhibited more efficient removal of the smear layer than the control group. The statistical analysis on the degree of erosion could not be performed because of the small number of specimens with evaluable areas.

\section{Discussion}

The main purpose of this investigation was two-fold: (1) evaluation of the effectiveness of three irrigating solutions (BioPure MTAD, 17\% EDTA, and 42\% citric acid) in removing the smear layer in the apical third of instrumented canals and (2) evaluation of the degree of erosion caused by these solutions. Because debridement in the apical third has always been a challenge, this area was the focus of this study.

The effectiveness of endodontic files, rotary instrumentation, irrigating solutions, and chelating agents to clean, shape, and disinfect root canals underpins the success, longevity, and reliability of modern endodontic treatments. Nevertheless, controversy still exists regarding the effectiveness of the myriad of file systems, ultrasonic irrigation, irrigating solutions, and chelating agents used to accomplish the chemomechanical cleansing of the root canal system (28). 

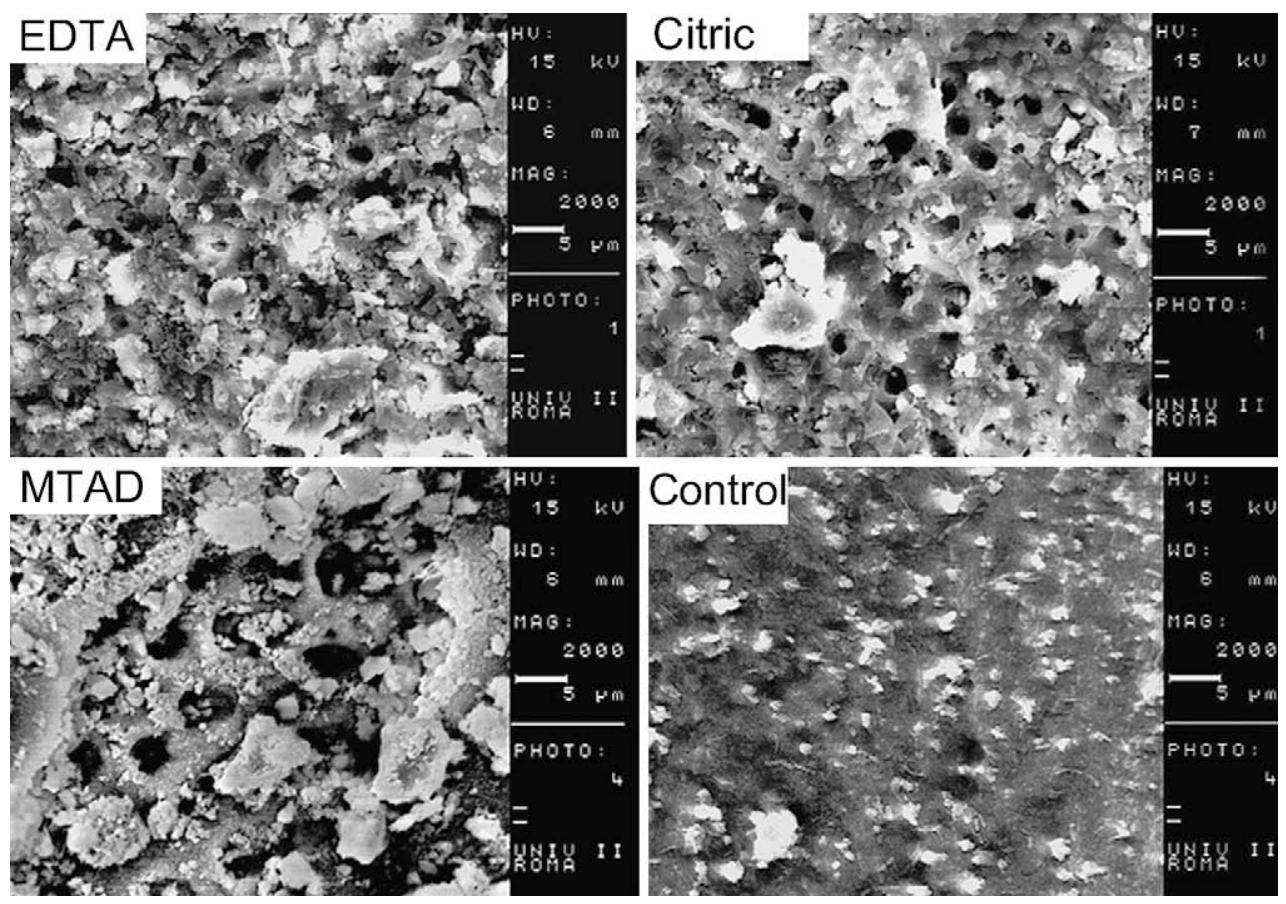

Figure 1. EDTA: $17 \%$ EDTA at the apical third, $2,000 \times$; citric: $42 \%$ citric acid at the apical third, $2,000 \times$; MTAD: MTAD at the apical third, $2,000 \times$; and control: control group at the apical third, $2,000 \times$.

Under the conditions of our ex vivo study, the following conclusions can be drawn: (1) BioPure MTAD, 17\% EDTA, or $42 \%$ citric acid did not cleanse endodontic walls in the apical third, and (2) the evaluation of the erosion in the apical third was not possible because none of the irrigants was able to completely remove the smear layer from the endodontic walls. Because the goal of the present work was restricted to a limited area of the three-dimensional endodontic system, the application of these results to the clinical situation is not straightforward.

Sodium hypochlorite solutions remain the most widely recommended irrigant in endodontics on the basis of its unique capacity to dissolve necrotic tissue remnants and excellent antimicrobial potency (29). However, in this study, sodium hypochlorite $5.25 \%$ at $37^{\circ} \mathrm{C}$ did not remove the smear layer from the apical third of the canals, which is consistent with results previously reported by some authors $(9,30)$.

In addition to NaOCl, the use of a chelating agent has been advocated to rid the root canal system of the smear layer. It is believed that removing this layer could dissolve attached microbiota and their toxins from root canal walls, improve the seal of root canal fillings, and reduce the potential of bacterial survival and reproduction $(2,3)$. However, the results from the present study showed that treatment with $1 \mathrm{~mL}$ of $17 \%$ EDTA $5.25 \% \mathrm{NaOCl} 37^{\circ} \mathrm{C}$ failed to clean the root canal system (Fig. 1) and left remnants of the smear layer in the apical third. This finding is essentially in agreement with previous studies indicating that this irrigating combination is less effective in the apical third of canals (9, 14, 15, 30, 31). Khedmat and Shokouhinejad (32) and Saito et al (33) showed results that are in accordance with ours, using similar volume, concentration, and time of application of EDTA at the apical third level. In contrast with our results, Mader et al (2), Calt and Serper (12), and 0'Connell et al (30) found that the combination of 17\% EDTA and $5 \% \mathrm{NaOCl}$ is an effective irrigating solution in removing the smear layer in the apical third of instrumented canals. These different results may be explained by the different volume of irrigants used (from 3 to 10 $\mathrm{mL}$ ) and rotary files used. It has been shown that the design of the cutting blade of rotary instruments can affect root canal cleanliness
(34). Lui et al (35) found that a 1-minute irrigation with 17\% EDTA followed by a final flush of $\mathrm{NaOCl}$ successfully achieved smear-free walls in instrumented root canals. This result might be attributable to the fact that the authors activated the irrigant solutions with an ultrasonic tip to within 1 to $2 \mathrm{~mm}$ of the root apex.

In our study, BioPure MTAD did not remove the smear layer from the apical third of the canals. This finding is in contrast with the results of Torabinejad et al $(14,15)$ showing an effective cleaning action with BioPure MTAD in the apical third. These discrepant findings can be explained by our use of $1 \mathrm{~mL}$ of the final irrigants for 1 minute, whereas Torabinejad et al followed the manufacturer's instruction using a total of $5 \mathrm{~mL}$ of the testing solution ( $1 \mathrm{~mL}$ per 5 minutes and then a flush with 4 $\mathrm{mL}$ ). We modified the time and volume in order to standardize the study procedure for the solutions tested.

Citric acid is a commonly used irrigant for smear layer removal at concentrations from $1 \%$ to $50 \%$ (22-26). In our study, citric acid $42 \%$ did not remove the smear layer from the apical third of the canals. These results are in agreement with studies of citric acid at different concentrations that reported differences in smear layer removal between the apical third and the other two thirds of root canals $(26,27,31,36$, 37). Thus, the available evidence indicates that the application of higher volumes of citric acid over 1 minute improves efficacy in removing the smear layer. Sterrett et al (38) showed that the effect of $10 \%$ citric acid on dentin demineralization was time dependent at 1,2 , and 3 minutes but was ineffective in removing the smear layer. Thus, the application of citric acid concentration higher than $42 \%$ for shorter times could improve apical third cleanliness.

The degree of erosion caused by the irrigants tested was one goal of our investigation. Only some specimens treated with the irrigants were analyzed for erosion because of heavy smear layer covering dentine tubule orifices. A significant analysis of the degree of erosion could not be performed because of the small areas devoid of smear layer and the few specimens with evaluable areas. For this reason, we concluded that none of the irrigating solutions showed erosion at the 
apical third although erosive effects of EDTA and citric acid have been reported in several studies $(12,31,39-41)$. BioPure MTAD is comparatively more aggressive in demineralizing intact intraradicular dentin and was able to expose collagen matrices 1.5 to 2 times as thick as those produced with EDTA (42).

\section{Conclusion}

Based on the results of this study, the application of $1 \mathrm{~mL}$ of BioPure MTAD, $17 \%$ EDTA, $42 \%$ citric acid, or $5.25 \% \mathrm{NaOCl} 37^{\circ} \mathrm{C}$ for 1 minute followed by $3 \mathrm{~mL}$ of $5.25 \% \mathrm{NaOCl}$ is not sufficient to completely remove the smear laver, especially in the apical third. Erosive effects of irrigants could not be analyzed. Further methodologically sound in vitro investigations of irrigating solutions, apical size, irrigation needles, and ultrasonic/sonic activation are needed for an appropriate evaluation of cleanliness and erosion of endodontic canals.

\section{References}

1. McComb D, Smith DC. A preliminary scanning electron microscopic study of root canals after endodontic procedures. J Endod 1975;1:238-42.

2. Mader CL, Baumgartner JC, Peters DD. Scanning electron microscopic investigation of the smeared layer on root canal walls. J Endod 1984;10:477-83.

3. Torabinejad M, Handysides R, Khademi AA, et al. Clinical implications of the smear laver in endodontics: a review. Oral Surg Oral Med Oral Pathol Oral Radiol Endod 2002;94:658-66.

4. Örstavik D, Haapasalo M. Disinfection by endodontic irrigants and dressings of experimentally infected dentinal tubules. Endod Dent Traumatol 1990;6:142-9.

5. White RR, Goldman M, Lin PS. The influence of the smeared layer upon dentinal tubule penetration by plastic filling materials. J Endod 1984;10:558-62.

6. Economides N, Liolios E, Kolokuris I, et al. Long-term evaluation of the influence of smear layer removal on the sealing ability of different sealers. J Endod 1999;25:123-5.

7. Shahravan A, Haghdoost AA, Adl A, et al. Effect of smear layer on sealing ability of canal obturation: a systematic review and meta-analysis. J Endod 2007;33:96-105.

8. Yamada RS, Armas A, Goldman M, et al. A scanning electron microscopic comparison of a high volume final flush with several irrigating solutions: part 3. J Endod 1983;9:137-42.

9. Ciucchi B, Khettabi M, Holz J. The effectiveness of different endodontic irrigation procedures on the removal of the smear layer: a scanning electron microscopic study. Int Endod J 1989;22:21-8.

10. Peters $\mathrm{OA}$, Barbakow $\mathrm{F}$. Effects of irrigation on debris and smear layer on canal walls prepared by two rotary techniques: a scanning electron microscopic study. J Endod 2000;26:6-10

11. Baumgartner JC, Mader CLA. Scanning electron microscopic evaluation of four root canal irrigation regimens. J Endod 1987;13:147-57.

12. Calt S, Serper A. Time-dependent effects of EDTA on dentin structures. J Endod 2002;28:17-9.

13. Niu W, Yoshioka T, Kobayashi C, et al. A scanning electron microscopic study of dentinal erosion by final irrigation with EDTA and $\mathrm{NaOCl}$ solutions. Int Endod J 2002;35:934-9.

14. Torabinejad M, Cho Y, Khademi AA, Bakland LK, Shabahang S. The effect of various concentrations of sodium hypochlorite on the ability of MTAD to remove the smear layer. J Endod 2003;29:233-9.

15. Torabinejad M, Khademi AA, Babagoli J, et al. A new solution for the removal of the smear laver. J Endod 2003;29:170-5

16. Torabinejad M, Johnson WB Irrigation solution and methods for use. US Patent $\&$ Trademark Office. United States Patent Application 20030235804; December 25, 2003 .
17. Torabinejad M, Shabahang S, Bahjri K. Effect of MTAD on postoperative discomfort: a randomized clinical trial. J Endod 2005;31:171-6.

18. Zhang W, Torabinejad M, Li Y. Evaluation of cytotoxicity of MTAD using the MTTtetrazolium method. J Endod 2003;29:654-7.

19. Bogardus JB, Blackwood RK Jr. Solubility of doxycycline in aqueous solution. J Pharm Sci 1979;68:188-94.

20. Shabahang S, Torabinejad M. Effect of MTAD on Enterococcus faecalis-contaminated root canals of extracted human teeth. J Endod 2003;29:576-9.

21. Baker PJ, Evans RT, Coburn RA, et al. Tetracycline and its derivatives strongly bind to and are released from the tooth surface in active form. J Periodontol 1983;54: 580-5.

22. Machado-Silveiro LF, González-López S, González-Rodríguez MP. Decalcification of root canal dentine by citric acid, EDTA and sodium citrate. Int Endod J 2004;37: 365-9.

23. Baumgartner JC, Brown CM, Mader CL, et al. A scanning electron microscopic evaluation of root canal debridement using saline, sodium hypochlorite, and citric acid. J Endod 1984;10:525-31.

24. Wayman BE, Kopp WM, Pinero GJ, et al. Citric and lactic acids as root canal irrigants in vitro. J Endod 1979;5:258-65.

25. Czonstkowsky M, Wilson EG, Holstein FA. The smear layer in endodontics. Dent Clin North Am 1990;34:13-25.

26. Pérez-Heredia M, Ferrer-Luque CM, González-Rodríguez MP. The effectiveness of different acid irrigating solutions in root canal cleaning after hand and rotary instrumentation. J Endod 2006;32:993-7.

27. Di Lenarda R, Cadenaro M, Sbaizero 0. Effectiveness of $1 \mathrm{~mol} \mathrm{L-1}$ citric acid and 15\% EDTA irrigation on smear laver removal. Int Endod J 2000;33:46-52.

28. Crumpton BJ, Goodell GG, McClanahan SB. Effects on smear layer and debris removal with varying volumes of $17 \%$ REDTA after rotary instrumentation. J Endod 2005;31:536-8.

29. Zehnder M. Root canal irrigants. J Endod 2006;32:389-98.

30. O'Connell MS, Morgan LA, Beeler WJ, et al. A comparative study of smear layer removal using different salts of EDTA. J Endod 2000;26:739-43.

31. Takeda FH, Harashima T, Kimura Y, et al. A comparative study of the removal of smear layer by three endodontic irrigants and two types of laser. Int Endod J 1999;32:32-9.

32. Khedmat S, Shokouhinejad N. Comparison of the efficacy of three chelating agents in smear laver removal. J Endod 2008;34:599-602.

33. Saito K, Webb TD, Imamura GM, et al. Effect of shortened irrigation times with $17 \%$ ethylene diamine tetra-acetic acid on smear layer removal after rotary canal instrumentation. J Endod 2008;34:1011-4.

34. Jeon IS, Spångberg LS, Yoon TC, et al. Smear layer production by 3 rotary reamers with different cutting blade designs in straight root canals: a scanning electron microscopic study. Oral Surg Oral Med Oral Pathol Oral Radiol Endod 2003;96:601-7.

35. Lui JN, Kuah HG, Chen NN. Effect of EDTA with and without surfactants or ultrasonics on removal of smear layer. J Endod 2007;33:472-5.

36. Goldman LB, Goldman M, Kronman JH, et al. The efficacy of several irrigating solutions for endodontics: a scanning electron microscopic study. Oral Surg Oral Med Oral Pathol Oral Radiol Endod 1981;52:197-204.

37. Zehnder M, Schmidlin P, Sener B, et al. Chelation in root canal therapy reconsidered. J Endod 2005;31:817-20.

38. Sterrett JD, Bankey T, Murphy HJ. Dentin demineralization. The effects of citric acid concentration and application time. J Clin Periodontol 1993;20:366-70.

39. De-Deus G, Paciornik S, Pinho Mauricio M, et al. Real-time atomic force microscopy of root dentin during demineralization when subjected to chelating agents. Int Endod J 2006;39:683-92.

40. Cergneux M, Ciucchi B, Dietschi JM, et al. The influence of the smear laver on the sealing ability of canal obturation. Int Endod J 1987;20:228-32.

41. Meryon SD, Tobias RS, Jakeman KJ. Smear removal agents: a quantitative study in vivo and in vitro. J Prosthet Dent 1987;57:174-9.

42. Tay FR, Pashley DH, Loushine RJ, et al. Ultrastructure of smear layer-covered intraradicular dentin after irrigation with BioPure MTAD. J Endod 2006;32:218-21. 